\title{
Chapter 6 \\ How the Global Code of Conduct Was Built
}

\begin{abstract}
How can an ethics code achieve impact? The answer is twofold. First, through adoption by influential research funders, who then make it mandatory for their award recipients. This is the case with the Global Code of Conduct for Research in Resource-Poor Settings, which was adopted by both the European Commission and the European and Developing Countries Clinical Trials Partnership shortly after its launch in 2018. Second, an ethics code can achieve impact when researchers use it for guidance whether it is compulsory or not. This is most likely to happen with codes that were developed transparently with all research stakeholders involved. This chapter will outline how the GCC was developed, and in particular how external stakeholders were systematically engaged, how existing codes were carefully analysed and built upon, and who the early adopters were.
\end{abstract}

Keywords Research ethics $\cdot$ Ethics dumping $\cdot$ Stakeholder engagement $\cdot$ Ethics codes

\section{Introduction}

The earliest research ethics codes were written solely for researchers:

The Nuremberg Code (1949) and the original Declaration of Helsinki (1964) made no mention of committee review; these documents placed on the investigator all responsibility for safeguarding the rights and welfare of research subjects. (Levine 2004: 2312)

In 1966, the surgeon general of the US Public Health Service issued a policy statement requesting the establishment of research ethics review committees or institutional review boards (Levine 2004: 2312). At this point in history, ethics codes would have had two main target audiences: researchers and research ethics committees.

The Global Code of Conduct for Research in Resource-Poor Settings (GCC) was developed from the start with three audiences in mind: researchers, research ethics 


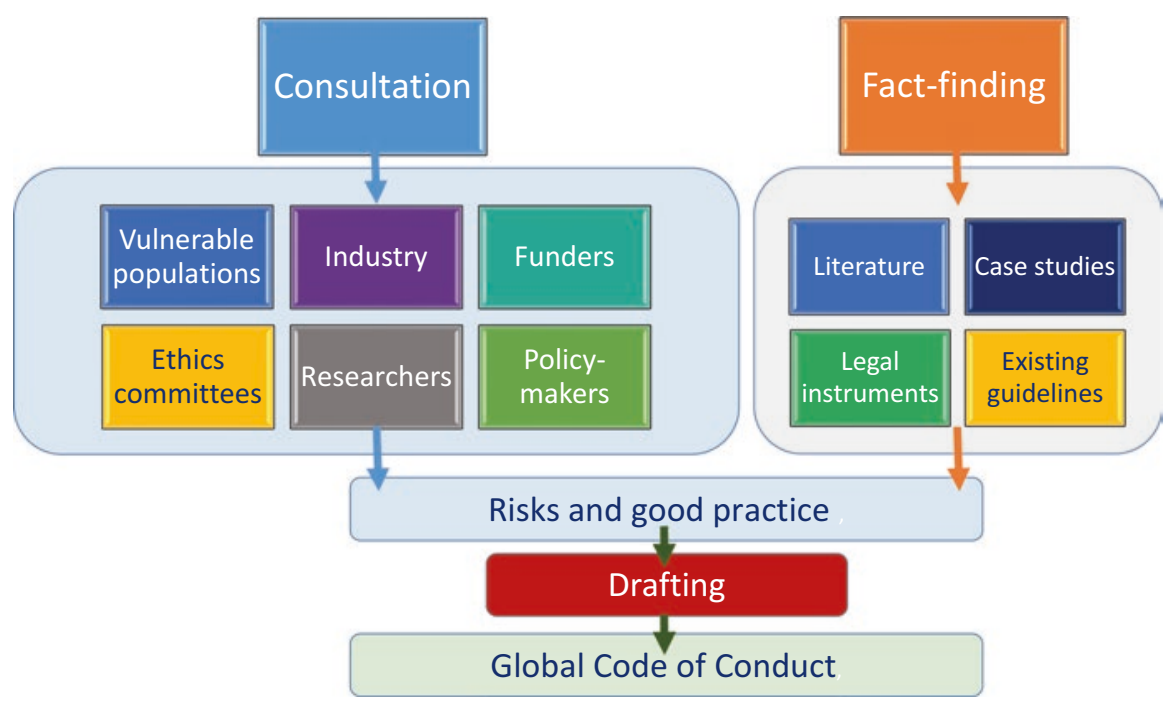

Fig. 6.1 Input into the GCC

committees and research participants (and/or their communities and support groups). To achieve a good match with these anticipated audiences, it was essential that all relevant stakeholders $^{1}$, in particular highly vulnerable populations, be included at all stages of the drafting process of the GCC. This inclusion was later praised by the Deputy Director-General for Research and Innovation of the European Commission (EC) as "impressive" and

a Horizon 2020 success story, [which] demonstrates that, in order to actively combat ethics dumping, ${ }^{2}$ a coordination of stakeholder efforts is required. Moreover, following the example of TRUST, ${ }^{3}$ such efforts should be based on a bottom-up approach that empowers local communities involved, as equal partners. (Burtscher 2018: 1)

A major benefit of the bottom-up approach is that it resulted in a short, clear code that is focused on practical matters and accessible to nonspecialists. The development process consisted of a range of activities, which are summarized in Figure 6.1.

Case studies were collected prior to the drafting of the GCC and published in a book entitled Ethics Dumping: Case Studies from North-South Research Collaborations (Schroeder et al. 2018). The foundation of the GCC, the risk matrix, has been introduced in Chapter 5 of this book.

\footnotetext{
1 "Stakeholders" is an increasingly contested term, as it may imply that all parties hold an equal stake. Some prefer the term "actors", yet this brings its own complexities. While acknowledging the debate, we use the well-established term "stakeholders" throughout.

${ }^{2}$ The export of unethical research from a high-income setting to a resource-poor setting with weaker compliance structures or legal governance mechanisms.

${ }^{3}$ The TRUST project (http://trust-project.eu/) was funded by the European Commission from 2015 to 2018. One of its outputs was the GCC.
} 
This chapter will outline the following steps in the development of the GCC:

- The consultations with various stakeholders over two and a half years

- The comparative analysis of existing guidelines and relevant legal instruments

- The drafting process.

\section{Meaningful Consultation with Diverse Stakeholders}

"They could take you out for coffee and call it consultation!” (Youdelis 2016)

Consultation, engagement, community engagement, guided discussions, focus groups and interviews: these are all means of obtaining relevant input from stakeholders prior to action. When a problem affects a range of people or groups and a feasible and implementable solution is sought, stakeholder input and community engagement are essential (Hebert et al. 2009; Cook 2008; Bassler et al. 2008; Dunn 2011).

This section shows how a wide range of stakeholders were consulted on ethics dumping concerns and potential solutions, with the specific aim of drafting the GCC. (Chapter 8 provides more general advice on community engagement with vulnerable populations (Chapter 8).)

\section{Broad Consultation}

Governance mechanisms such as ethics codes require evidence of legitimacy. Why should a particular ethics code be followed by researchers? The answer that can be given for the GCC is fourfold. First, the funder that supported the development of the GCC - the European Commission - requested a new code to guard against ethics dumping. Hence, instead of engaging in a long-term process to negotiate the addition of specific sections on international collaborative research to existing ethics codes and governance mechanisms, a funder with an interest in the output opted for a new and independent code. Second, in 2015 the TRUST consortium's bid was chosen by peer reviewers from a range of proposals to tackle ethics dumping. The criteria for the selection were excellence and impact, as well as the quality and efficiency of the proposed implementation (Horizon $2020 \mathrm{nd}$ ). Third, upon the completion and launch of the GCC in 2018, the EC ethics and integrity sector and the EC legal department assessed the code and the decision was taken to make it a mandatory reference document for European Union (EU) framework programmes (Burtscher 2018). However, the most important element for the GCC's credibility may be the fourth element, the fact that the TRUST consortium made every possible effort to engage all relevant stakeholders across five continents in the development of the GCC. 
In the effort to reach all relevant stakeholders, the TRUST consortium first had to agree upon who needed to be consulted on ethics dumping in research. The following six groups were identified:

1. The research process starts with research policymakers, who set the parameters for research activities. For instance, in the European Union, research aimed at human cloning for reproductive purposes is forbidden (European Commission 2013), which means it is outside the activity range of researchers.

2. A second highly influential stakeholder group consists of research funders. Without specific funding, most research is not possible. Whether research funding is provided by industry, charitable foundations or state-funded research programmes makes no significant difference. All funders are of particular importance in tackling ethics dumping, as they often set specific ethical rules that the researchers they fund must adhere to.

3. Researchers design research projects and work directly with participants and communities during implementation. It is normally they who are responsible for ethics dumping, whether deliberate or inadvertent.

4. Many studies involve human research participants who are directly affected by the research. As ethics dumping can also affect animals and the environment, groups working to defend them against unethical treatment could count as advocates - that is, persons who act on behalf of other entities. The same applies to nongovernmental organizations (NGOs) or think-tanks that promote the interests of those who cannot defend themselves against exploitation, or who struggle to do so. Hence, these groups are included in the list of stakeholders.

5. Negative impacts from unethical research conduct can extend beyond research participants and cause harm to community members. In genetic research, for instance, research results are likely to be relevant to close family members who were not involved in the study (Gallo et al. 2009). Similarly, a research participant might divulge valuable traditional knowledge held by a community, which cannot be used ethically (or even, sometimes, legally) by the researcher unless s/he has also engaged the wider community (Wynberg et al. 2009).

6. The final group that can count as a major stakeholder in research consists of research ethics committees, which review and approve research proposals on behalf of funders or research institutions. This is especially important when tackling ethics dumping, as the role of research ethics committees is to safeguard the rights and welfare of those involved in research (Levine 2004: 2312).

Figure 6.2 graphically depicts the main parties involved in research, and therefore represents the research stakeholders in the fight against ethics dumping.

There were budget-holding representatives from each of these research stakeholder groups in the TRUST project consortium (see Table 6.1). This meant that even before outward engagement to draft the GCC, a lot of information could be generated internally.

As Table 6.1 shows, considerable expertise from different stakeholder perspectives was available internally. In addition, input was sought from external experts, who engaged through four channels, facilitated by six enablers, to participate in the development of a range of project outputs, one of which was the GCC. This approach is detailed in Figure 6.3 (Dammann and Cavallaro 2017). 


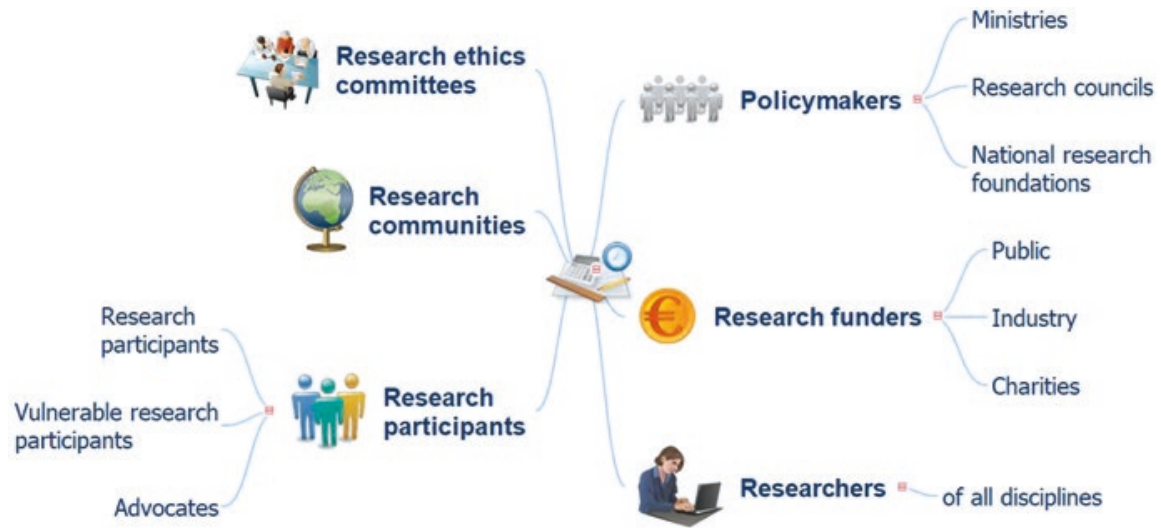

Fig. 6.2 Research stakeholders

Table 6.1 Main research stakeholders involved as TRUST budget holders

\begin{tabular}{l|l}
\hline $\begin{array}{l}\text { Stakeholder } \\
\text { type }\end{array}$ & TRUST partner \\
\hline $\begin{array}{l}\text { Research } \\
\text { policymakers }\end{array}$ & $\begin{array}{l}\text { The United Nations Educational, Scientific and Cultural Organization } \\
\text { (UNESCO) promotes policy frameworks for research through drafting } \\
\text { internationally focused guidelines on scientific co-operation. } \\
\text { The "Institut national de la santé et de la recherche médicale"® (Inserm) holds } \\
\text { responsibility for the strategic, scientific and operational coordination of } \\
\text { French biomedical research. }\end{array}$ \\
\hline $\begin{array}{l}\text { Research } \\
\text { funders }\end{array}$ & $\begin{array}{l}\text { The European and Developing Countries Clinical Trials Partnership (EDCTP) } \\
\text { funds research for the prevention and treatment of poverty-related infectious } \\
\text { diseases in sub-Saharan Africa. } \\
\text { The Swiss-based Global Values Alliance (GVA) is a foundation that focuses } \\
\text { on engagement with pharmaceutical industry partners as its main role in the } \\
\text { TRUST project }\end{array}$ \\
\hline Researchers & $\begin{array}{l}\text { The Centre for Professional Ethics at the University of Central Lancashire is } \\
\text { one of the oldest research-only ethics centres in Europe, with specialist } \\
\text { expertise in global justice issues. } \\
\text { The Bio-Economy Research Chair at the University of Cape Town and her } \\
\text { team focus on engagement with communities, indigenous knowledge holders } \\
\text { and policymakers to ensure environmentally sustainable poverty reduction. } \\
\text { The Law School of the University of the Witwatersrand, Johannesburg, } \\
\text { contributed specialist human rights and legal frameworks expertise. }\end{array}$ \\
\hline $\begin{array}{l}\text { Research } \\
\text { advocates } \\
\text { organizations })\end{array}$ & $\begin{array}{l}\text { Many of the individuals involved in drafting the GCC have previously been } \\
\text { research participants. Of particular importance in this process were the } \\
\text { indigenous peoples and sex worker representatives who were involved } \\
\text { through SASI and PHDA (see "Research communities" below). }\end{array}$ \\
\hline $\begin{array}{l}\text { The Council on Health Research for Development (COHRED) helps promote } \\
\text { the health and development of populations in low- and middle- income } \\
\text { countries. } \\
\text { Action Contre La Faim (ACF) is recognized as one of the leading } \\
\text { organizations in the fight against hunger worldwide. ACF undertakes its own } \\
\text { research on highly vulnerable populations. }\end{array}$ \\
\hline ants
\end{tabular}


Table 6.1 (continued)

\begin{tabular}{l|l}
\hline $\begin{array}{l}\text { Stakeholder } \\
\text { type }\end{array}$ & TRUST partner \\
\hline $\begin{array}{l}\text { Research } \\
\text { communities }\end{array}$ & $\begin{array}{l}\text { The South African San Institute (SASI) is dedicated to serving the San } \\
\text { communities of southern Africa through legal, advocacy, socio- } \\
\text { anthropological and related services. } \\
\text { Partners for Health and Development in Africa (PHDA) supports female and } \\
\text { male sex workers in the low socio-economic strata who reside in the informal } \\
\text { settlements of Nairobi. }\end{array}$ \\
\hline $\begin{array}{l}\text { Research ethics } \\
\text { reviewers }\end{array}$ & $\begin{array}{l}\text { The Forum for Ethics Review Committees in India (FERCI) promotes the } \\
\text { effective implementation of the ethical review of biomedical research studies } \\
\text { in India. }\end{array}$ \\
\hline
\end{tabular}

- Advisory board

- Engagement panel

- Stakeholder inventory

- Funder platform

- Industry platform

- Case study competition

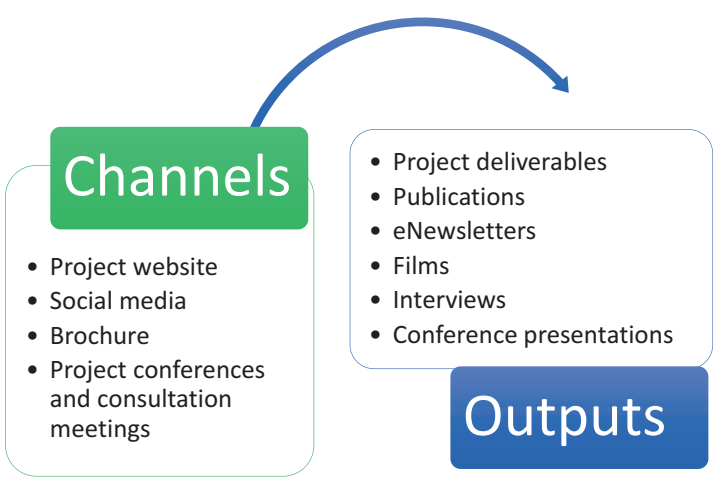

Fig. 6.3 TRUST communication and engagement strategy

External engagement prior to drafting the GCC was extensive. The elements of the communication and engagement strategy that were specifically relevant to the drafting of the GCC are described in more detail below, namely:

- A case study competition

- Project conferences and consultation meetings

- Funder and industry platforms

\section{The Case Study Competition}

As the GCC was designed to address the risks of ethics dumping, it was essential to analyse as many actual examples of ethics dumping as possible. To reach out to stakeholders who were not connected with existing networks, a competition to describe cases of ethics dumping was launched in 2016. Applicants from around the world were invited to submit short abstracts of ethics dumping cases, which involved research undertaken in low- and middle- income countries (LMICs) conducted by researchers, sponsors or funders from high-income countries (HICs). Cases could 
report on events related to any research field. A judging committee selected by TRUST ranked the best ten abstracts, and shortlisted applicants were invited to submit a full case study. Rewards for the authors of the best five cases were $€ 2,000$ each and $€ 1,000$ each for five runners-up. Following peer review, eight full-length case studies were selected for inclusion in Ethics Dumping: Case Studies from NorthSouth Research Collaborations (Schroeder et al. 2018) or as learning materials for the GCC website (http://www.globalcodeofconduct.org). This mechanism expanded the material available for the development of the risk matrix considerably.

\section{Meetings and Platforms: Reaching the Right Delegates}

"Around the world, millions of meetings are being held every day - most of them unproductive" (Koshy et al. 2017). In "Not Another Meeting!" Rogelberg et al. (2006) establish that perceived meeting effectiveness has a strong, direct relationship with positive job attitudes and wellbeing at work. In the literature, meeting efficiency is linked to questions such as, "Is a meeting necessary?" (Koshy et al. 2017), or "Is a meeting the most cost-effective way of obtaining an outcome?" (Rogelberg et al. 2006). In addition, advice is given on how to make meetings more efficient, such as, "Prepare the agenda in advance," and "Start with the most strategic items," (Rogelberg et al. 2006).

For the TRUST consortium, the most important question ahead of all major consultation meetings was: "Who are the external delegates?" On the one hand, are they senior and/or from influential institutions? Or, on the other hand, do they have firsthand experience of ethics dumping? In other words, the consortium aimed for senior decision-maker representation as well as vulnerable population representation. To give an example of the former, Table 6.2 shows the funders and companies which were represented at the funder and industry consultation. The consultation with vulnerable populations on engagement with research participants will be described below.

As noted above, millions of meetings are held every day around the world, and many of them affect job satisfaction and wellbeing negatively. How, then, could a meeting hosted on behalf of a three-year research project achieve such impressive representation? There were four reasons for this success:

1. A convincing justification for the meeting secured a Wellcome Trust venue in central London. The Wellcome Trust is the largest private funder of medical research globally (Jack 2012), with a very high standing in research circles.

Table 6.2 Funders and industry members represented at consultation meeting, London 2017

\begin{tabular}{l|l}
\hline Funders & Industry members \\
\hline Wellcome Trust & European Federation of Pharmaceutical Industries and \\
European Commission. & Associations (EFPIA) \\
Medical Research Council & Sanofi \\
UKRI & Roche \\
World Health Organization TDR & Novartis \\
Calouste Gulbenkian Foundation & GlaxoSmithKline \\
Global Forum on Bioethics in & Boehringer Ingelheim \\
Research &
\end{tabular}


2. Invitations to funders were issued by the European and Developing Countries Clinical Trials Partnership (EDCTP), the high-profile funding institution represented on the TRUST consortium.

3. Invitations to industry were issued by Professor Klaus Leisinger, a member of the TRUST consortium and former personal adviser on corporate responsibility to UN Secretary-Generals Kofi Annan and Ban Ki-moon.

4. Most important to the success, however, were the prior activities of the funder and industry platforms.

TRUST's Funder Platform was established by the EDCTP in 2016 via the following steps:

- Development of an inventory of major funders of basic and operational/implementation research around the world.

- Obtaining the names of those whose expertise included research ethics in LMICs, ethics committees in LMICs, adherence to ethical standards, ethics codes and best practice.

- Introduction of the project and its aims (e.g. the GCC) in personal, tailored communications to the experts identified.

- Personal invitations to the funder consultation meeting in London.

- Personal, tailored follow-up communication after the meeting.

Policymakers at the highest UN level have selected the pharmaceutical sector for special responsibilities towards LMICs, and therefore this sector was chosen for engagement activities with industry in TRUST. Both the Millennium Development Goals ${ }^{4}$ and the Sustainable Development Goals ${ }^{5}$ call on the pharmaceutical industry for special assistance to LMICs. In addition, the sector suffers from considerable mistrust among the general population with regard to international collaborative research and the potential exploitation of LMICs (Kessel 2014).

TRUST's Industry Platform was established in 2016 by Professor Leisinger in the same manner as the Funder Platform, with the following addition:

- Webinars and personal meetings were organized through EFPIA, at which Professor Leisinger explained the ambitions of the TRUST project and the need for pharmaceutical companies to contribute.

Through this extensive preparation, it was possible to introduce draft ideas for the GCC at a high-profile and well-attended consultation meeting in London in June 2017, and to engage delegates sufficiently to secure further input, nine months later, on the first semipublic draft of the GCC.

Figure 6.4 gives an overview of the various project conferences and consultation meetings at which information was sought to counter ethics dumping. ${ }^{6}$

\footnotetext{
${ }^{4}$ Goal 8, Target 4: "in cooperation with pharmaceutical companies, provide access to affordable essential drugs in developing countries" (United Nations ndb).

${ }^{5}$ Goal 3, Target 3.8: "Achieve universal ... access to safe, effective, quality and affordable essential medicines and vaccines for all" (United Nations nda).

${ }^{6}$ The meetings had a range of other purposes, many of which are not relevant here and are therefore not included in this summary.
} 


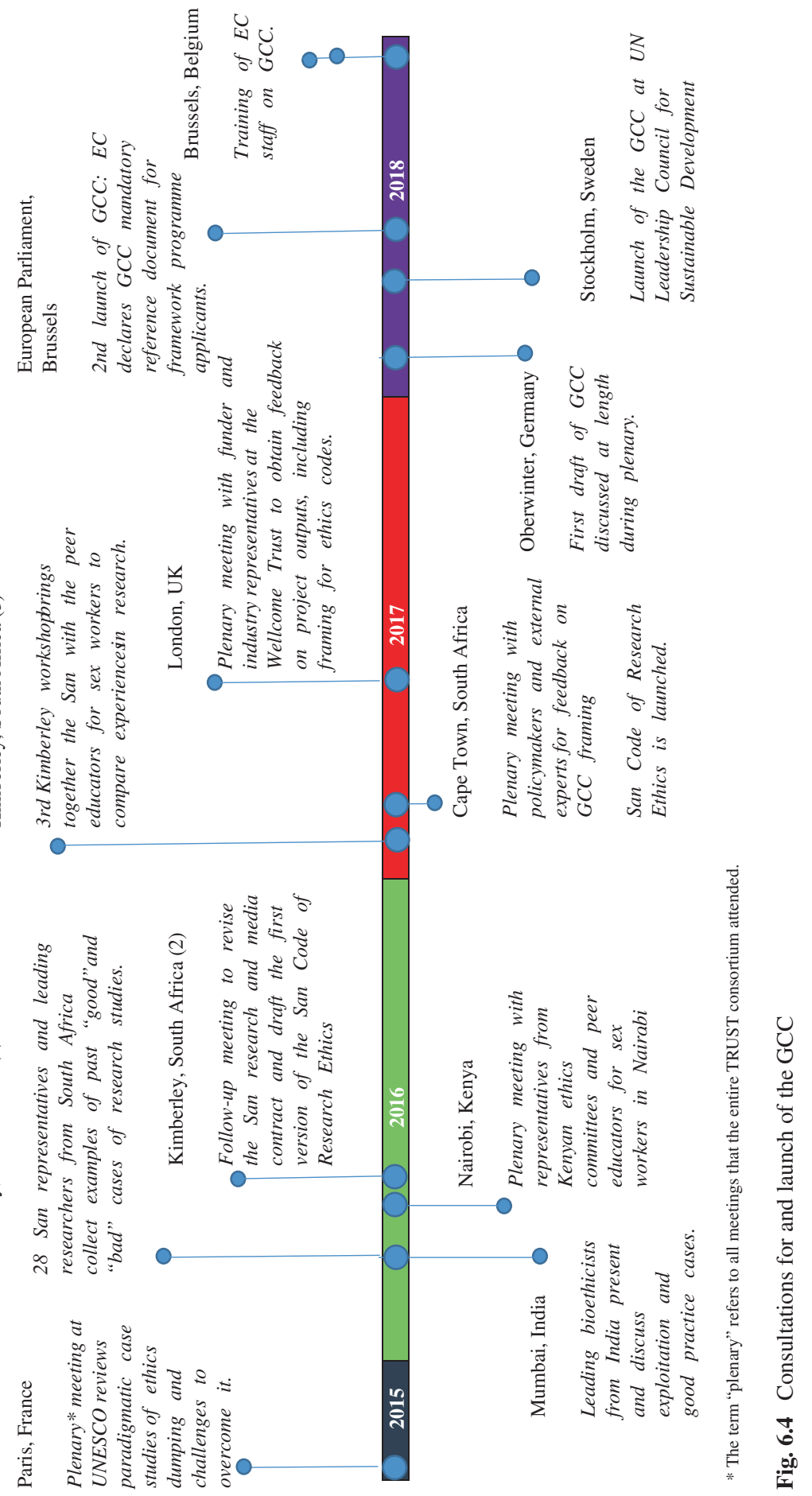


Returning to the six research stakeholder groups identified earlier, the next section details how each group was reached through project conferences and consultation meetings.

\section{External Engagement with Research Policymakers}

National research foundations, research councils and government ministries guide the strategic direction of research. Representatives from all of these groups attended the TRUST plenary in Cape Town in 2017, in particular senior representatives from the following national bodies:

- The South African Department of Science and Technology

- The South African Department of Environmental Affairs

- The South African National Research Foundation

- The Zimbabwean Agricultural Research Council

To give an example of input, articles $1^{7}$ and $4^{8}$ of the GCC are directly linked to input from research policymakers. Dr Isaiah Mharapara from the Zimbabwean Agricultural Research Council argued that agricultural research in Africa had largely been based on foreign principles, meaning that the continent's own crops, fruits, insects, fish and animals had been ignored. Through the historical introduction of Western agricultural systems and cash crops such as tobacco, as well as genetically engineered crops, Africa had failed to develop agricultural solutions adapted to local conditions. According to Dr Mharapara, a lack of financial resources meant that African nations had been, and still were, vulnerable to exploitation by foreign researchers. This had resulted in damage to ecological systems, the loss of soils, fertility, biodiversity and natural resilience, and the erosion of indigenous knowledge. He advocated inclusive, consultative, robust and agreed processes to establish equitable research partnerships (Van Niekerk et al. 2017).

\section{External Engagement with Research Funders}

Estimates for research and development expenditure in the European Union in 2016 indicate that $56.6 \%$ of all such expenditure comes from the business sector, $30.9 \%$ from the government sector and the remainder mostly from charitable foundations (Eurostat 2018). TRUST's main consultation workshop for research funders was held in London in 2017 and involved all three sectors: public funders, private

\footnotetext{
${ }^{7}$ Local relevance of research ... should be determined in collaboration with local partners.

${ }^{8}$ Local researchers should be included, wherever possible, throughout the research process, including in study design, study implementation, data ownership, intellectual property and authorship of publications.
} 
Table 6.3 Good practice input from funders and industry with GCC output

\begin{tabular}{l|l}
\hline Good practice & Relevant GCC article \\
\hline $\begin{array}{l}\text { Ensuring double } \\
\text { ethics review }\end{array}$ & Article 10: Local ethics review should be sought wherever possible. \\
\hline $\begin{array}{l}\text { Community } \\
\text { engagement }\end{array}$ & $\begin{array}{l}\text { Article 2: Local communities and research participants should be } \\
\text { included throughout the research process. }\end{array}$ \\
\hline $\begin{array}{l}\text { Clear roles and } \\
\text { responsibilities }\end{array}$ & $\begin{array}{l}\text { Article 20: A clear understanding should be reached among collaborators } \\
\text { with regard to their roles, responsibilities and conduct throughout the } \\
\text { research cycle. }\end{array}$ \\
\hline
\end{tabular}

funders and charitable funders of research (see Table 6.2). The three main good practice elements ${ }^{9}$ raised by funders and industry to stop ethics dumping are listed in Table 6.3, with their corresponding GCC articles (Singh and Makanga 2017).

As already indicated, engagement with research funders was not restricted to one meeting, but took place over approximately two years via the funder and industry platforms described above. Additionally, the first draft of the GCC was distributed to all members of the platforms nine months after the workshop. Both groups provided further comments on the draft.

\section{External Engagement with Researchers}

The consortium that drafted the GCC represented a wide range of academic disciplines, namely ethics, medicine, economics, bioethics, law, social psychology, sociology, psychology, gender studies, chemistry, social sciences, psychiatry, biology, zoology, veterinary medicine, political science and management. The multidisciplinary nature of the consortium's expertise enabled broad engagement with the wider academic community. For example, academic presentations that included the GCC were delivered in Belgium, China, Congo, Cyprus, Germany, India, Kenya, Latvia, the Netherlands, the Philippines, Portugal, Rwanda, South Africa, Sweden, Taiwan, Uganda, Vatican City, the UK and the USA (Dammann and Schroeder 2018).

The feedback from researchers was essentially threefold. First, researchers were interested in the potential "grey areas" of ethics dumping. A question in this context, asked on many occasions by different audiences, was: "If a particular research study has no real local relevance to LMICs, and the research money spent by wellintentioned researchers from HICs (who genuinely believe that they are improving the world) is in fact being wasted, does that count as ethics dumping?" A case in

\footnotetext{
${ }^{9} \mathrm{~A}$ fourth good practice element that was emphasized at the funder and industry workshop was the provision of post-trial access to successfully marketed drugs. This requirement was not included in the GCC for two main reasons. First, the GCC was designed to be applicable to all disciplines, and hence articles with limited applicability were avoided. Second, post-trial access is clearly indicated in existing guidelines, in particular in the Declaration of Helsinki (WMA 2013). A good practice example of post-trial access was included in a TRUST special symposium on industry obligations towards LMICs (see Kelman et al. 2019).
} 
point has been described by Van Niekerk and Wynberg (2018). Northern researchers were working on a genetically modified banana with a purportedly enhanced vitamin content, the ultimate aim being to alleviate nutritional deficiencies in Uganda. However, it turned out that existing local varieties provided a higher vitamin content than the envisaged GM variety. The question of whether that should count as ethics dumping goes back to a long-standing dilemma for ethics committees: Is bad science bad ethics? (Levine 2004) Wasteful research cannot be put into the same category as the wilful exploitation of lower regulatory standards to exploit research populations in LMICs for individual gain. But at the same time, with such a pressing need for innovative solutions to LMIC problems, the violation of article 1 of the GCC (local relevance of research) and the avoidable waste of limited funding resources must count as unethical.

A second recurring response to the GCC from researchers has been that "everyone loved our values". ${ }^{10}$ Audiences in HICs - England, for instance - even asked whether they could use the four values in national research in their own countries. Hence, rather than seeing the values as solely applicable when there are vast power differentials between researchers and research participants (as between HICs and LMICs), they were keen to use them in any research.

A third recurring issue for researchers has been the following: "We appreciate that the code is short and accessible, but wouldn't a longer, more detailed code give more support to early career researchers?" The TRUST consortium agreed upon a concise code because it is vital that the demands of substance for each article be clear and straightforward, while the process demands remain flexible. Let us take article 1 as an example:

The substance element of article 1 is: "Local relevance of research is essential". Further information would not be helpful to early career (or any other) researchers.

The process element of article 1 is: "[Local relevance] should be determined in collaboration with local partners." This could only be set out in more detail if there were a single process that would fit every situation - and that is not the case. What an equitable process for determining research goals should look like in an international collaborative research project is one of the things that need to be agreed on within the process of that project. Hence, prescriptive details would have been counterproductive to the very spirit of the article.

Instead of attempting to formulate a range of possibilities to fill the process elements with substance, we opted to provide educational material to support the GCC online, ${ }^{11}$ because any process requirements are best agreed between the relevant partners rather than imposed prescriptively by code drafters. Hence, our educational materials future-proof the GCC, as they can be updated in real time for use by early career (or any other) researchers, and, unlike the GCC itself, they are not mandatory.

\footnotetext{
${ }^{10}$ Personal communication from Dr Vasantha Muthuswamy, a TRUST project team member, after a GCC presentation in Taiwan.

${ }^{11} \mathrm{http} / / /$ www.globalcodeofconduct.org/
} 


\section{Engagement with Research Participants and Research Communities}

The inclusion of the perspectives of research participants and research communities who are vulnerable to exploitation, and therefore to ethics dumping, was essential to our bottom-up approach. It is also the ethical approach, as stipulated in article 2 of the GCC:

Local communities and research participants should be included throughout the research process, wherever possible, from planning through to post-study feedback and evaluation, to ensure that their perspectives are fairly represented. This approach represents Good Participatory Practice.

Two NGO partners in the TRUST project were tasked specifically with ensuring that the voices of vulnerable populations were heard and acted upon. First, the South African San Institute (SASI) made the inclusion of indigenous peoples from South Africa possible. While San leaders and representatives were involved in all the work of the TRUST project, including the drafting of the GCC, the full impact of their contribution is best understood through the account in Chapter 7 of this book of the development of the San Code of Research Ethics. Second, Partners for Health and Development in Africa (PHDA) made the inclusion of sex workers from the Majengo area of Nairobi possible. At this point we will focus on their involvement in order to illustrate the bottom-up approach of the GCC drafting process.

PHDA is a nonprofit organization that undertakes work in the fields of health and development in Kenya. Its mission is to increase access to health for disadvantaged communities in Africa by strengthening health systems, research, programme development and partnerships. PHDA's programmes are implemented by a collaborative group of scientists and public health professionals from the University of Manitoba (Canada), the University of Nairobi and the government of Kenya. Its work focuses mainly on HIV prevention, treatment and care, research, capacity-building and training.

The Sex Workers Outreach Programme (SWOP) is a PHDA initiative that undertakes active community engagement and provides clinical and preventative services to 33,000 sex workers residing in Nairobi. These sex workers would otherwise find access to medical services in public health facilities extremely limited due to stigma and discrimination. Those enrolled in the sex workers cohort for HIV prevention services are free to volunteer for available research studies after providing informed consent. Most studies are on the epidemiology of sexually transmitted diseases, and on host genetic factors that influence infectivity and disease progression.

Given that sex work is illegal in Kenya, we cannot assign input to specific, named individuals here. Suffice to say that the personal contributions of courageous and admirable sex workers, both female and male, provided the TRUST team not only with practical advice that took shape in specific articles of the GCC, but also with inspiration. Table 6.4 presents two examples of issues raised by the Nairobi sex workers (Chatfield et al. 2016a) that were implemented in the GCC. 
Table 6.4 Input from sex workers and GCC connection

\begin{tabular}{l|l}
\hline Issues raised by sex workers & Relevant GCC Article \\
\hline "We need feedback to the community from the & $\begin{array}{l}\text { Article 3: Feedback about the findings of the } \\
\text { research in simple and non-scientific language. } \\
\text { research must be given to local communities and } \\
\text { research participants. It should be provided in a } \\
\text { way results have been shared with us in the } \\
\text { past, but I did not know what they meant. Do } \\
\text { not give us results in scientific language. It } \\
\text { puts us at risk if we do not understand the } \\
\text { results. ... Come back with the results and tell } \\
\text { us how we can make our lives better." }\end{array}$ \\
$\begin{array}{l}\text { "We know that the samples that are collected } \\
\text { from us are sometimes sent to other countries. } \\
\text { What happens to them? In my culture - if my } \\
\text { blood is taken, it must come back to me and I } \\
\text { bury it. ... [L]ocal and cultural values should } \\
\text { be taken into account." }\end{array}$ & $\begin{array}{l}\text { Article 8: Potential cultural sensitivities should } \\
\text { communities, research participants and local } \\
\text { researchers to avoid violating customary } \\
\text { practices. ... If researchers from high-income } \\
\text { settings cannot agree on a way of undertaking } \\
\text { the research that is acceptable to local } \\
\text { stakeholders, it should not take place. }\end{array}$ \\
\hline
\end{tabular}

The main message that the TRUST team has been promoting since the meetings with the Nairobi sex workers has been: "Let representatives of vulnerable populations speak for themselves" (Schroeder and Tavlaki 2018). As a result, a former sex worker from Nairobi brought the demands of her community to the European Parliament to great acclaim (TRUST 2018).

\section{Advocate Voices for Animals}

A senior veterinarian, Professor David Morton, was involved throughout the TRUST project as an adviser. At a plenary meeting in Cape Town, he described how animals had no voice and therefore no choice about involvement in research. He asked: "Who consents on behalf of animals?"

There are currently no globally agreed ethical standards for research involving animal experimentation, and regulation varies from country to country. In the EU, animal experiments are governed by Directive 2010/63/EU, known as the Animal Experiments Directive, which stipulates measures that must be taken to replace, reduce and refine (the "Three Rs"12) the use of animals in scientific research. Among other requirements, it lays down minimum standards for housing and care and regu-

\footnotetext{
${ }^{12}$ The "Three Rs" are the underpinning requirements of most policies and regulations in animal research:

$\rightarrow$ Replacement: Methods that avoid or replace the use of animals.

$\rightarrow$ Reduction: Methods that minimize the number of animals used per experiment.

$\rightarrow$ Refinement: Methods that minimize suffering and improve welfare.
} 
lates the use of animals through systematic project evaluation that requires the assessment of pain, suffering, distress and lasting harm caused to the animals.

Some researchers knowingly exploit variations in standards and opt to conduct animal studies in LMICs because it is cheaper and/or because regulation is less strict than in HICs (Morton and Chatfield 2018). For example, researchers might conduct experiments on non-human primates in an LMIC setting that would be illegal in their HIC home country.

For research collaborations between groups in different countries, partners may find that they are confronted with different ethical standards for animal experimentation. In such cases ethical standards should comply with the highest ethical standards rather than be adjusted to the lowest common denominator. Hence the GCC states that standards for animal research in international collaborative research must comply with those that are more demanding and protective of animal welfare (article 17).

\section{External Engagement with Research Ethics Committees}

The main engagement meetings with research ethics reviewers and chairs of research ethics committees took place in India (2016) and Kenya (2017).

The Forum for Ethics Review Committees in India is led by Dr Vasantha Muthuswamy, who was responsible for issuing the Indian Council of Medical Research's Ethical Guidelines for Biomedical Research on Human Subjects in 2000 and the revised version, Ethical Guidelines for Biomedical Research on Human Participants, in 2006, and also contributed to the most recently launched version in 2017. At her invitation, 30 leading bioethicists from India came together with guests from Europe in a two-day workshop in Mumbai in 2016. This workshop, which was attended by many senior research ethics committee chairs and members, was an important fact-finding mission in the early stages of the project. Cases of exploitation were collated and good practice in research involving LMICs discussed (Chatfield et al. 2016b).

Further in-depth consultation with ethics committee chairs formed part of a plenary workshop in Nairobi in 2017. TRUST received valuable input from three esteemed ethicists: Professor Elizabeth Bukusi (Deputy Director Research and Development, Kenya Medical Research Institute), Professor Anastasia Guantai (Kenyatta National Hospital) and Professor Kirana Bhatt (Chair of the National Bioethics Committee, University of Nairobi), who shared their respective experiences, concerns and insights. Table 6.5 summarizes some of the issues raised (Chatfield et al. 2016b) and their relationship to the final GCC. 
Table 6.5 Input from research ethics committee chairs and GCC output

\begin{tabular}{l|l}
\hline Input & Relevant GCC article \\
\hline $\begin{array}{l}\text { Intellectual property } \\
\text { rights are often held } \\
\text { only in the North. }\end{array}$ & $\begin{array}{l}\text { Article 4: Local researchers should be included, wherever possible, } \\
\text { throughout the research process, including in study design, study } \\
\text { implementation, data ownership, intellectual property and authorship of } \\
\text { publications. }\end{array}$ \\
\hline $\begin{array}{l}\text { Attempts at gaining } \\
\text { ethics approvals can } \\
\text { be extremely late. }\end{array}$ & $\begin{array}{l}\text { Article 11: Researchers from high-income settings should show respect to } \\
\text { host country research ethics committees. }\end{array}$ \\
\hline $\begin{array}{l}\text { LMIC partners' } \\
\text { tasks are restricted } \\
\text { to obtaining data. }\end{array}$ & $\begin{array}{l}\text { Article 4 (see above) } \\
\text { Article 20: A clear understanding should be reached among collaborators } \\
\text { with regard to their roles, responsibilities and conduct throughout the } \\
\text { research cycle. }\end{array}$ \\
\hline $\begin{array}{l}\text { Why does } \\
\text { biological material } \\
\text { need to be shipped } \\
\text { abroad? }\end{array}$ & $\begin{array}{l}\text { Article 5: Access by researchers to any ... human biological materials ... } \\
\text { should be subject to the free and prior informed consent of the owners or } \\
\text { custodians. Formal agreements should govern the transfer of any material } \\
\text { or knowledge to researchers, on terms that are co-developed with resource } \\
\text { custodians or knowledge holders. }\end{array}$ \\
\hline
\end{tabular}

\section{Analysis of Existing Guidelines}

We have summarized above the extensive consultation activities of the TRUST project prior to the actual drafting of the GCC. Aside from these valuable contributions, it was also vital that the GCC should not set out to "reinvent the wheel". Given the vast number of existing guidelines, and the significant expertise that went into drafting them, it was important for us to link the GCC to those existing guidelines so as to produce something that did not replicate earlier work, but rather complemented it.

Research ethics committees have been in operation since the 1960s (Levine 2004). The earliest codes of research ethics are even older (Levine 2004). Yet the ethics dumping cases identified as part of the fact-finding mission for the GCC occurred mostly in the 2010s (Schroeder et al. 2018), more than 50 years after the first codes and committees became operational. There are many reasons why ethics dumping in research persists, one of which is that the constraints on research ethics committees in LMICs make them vulnerable to exploitation, often across the NorthSouth global divide. Some such constraints are summarized in Table 6.6 (modified from Nyika et al. 2009).

A new code of ethics cannot, by itself, resolve these issues, for instance the lack of resources to fund effective ethics review. However, it can tailor requirements to LMIC needs. To do so most effectively, the TRUST team decided that it would not base the drafting process on existing ethics guidelines, because, as is also noted in Chapter 4, the history of research ethics review is heavily built on the United States experience and context and focused on medical research (see also Levine 2004). To avoid any potential bias, the following approach was agreed upon. First, the exercise of identifying ethics dumping risks was to be carried out without reference to existing ethics guidelines. Second, only once the risks had been identified through fact- 
Table 6.6 Constraints on African research ethics committees

\begin{tabular}{l|l}
\hline Insufficiency of resources & $\begin{array}{l}\text { No or poor support by the hosting } \\
\text { institution }\end{array}$ \\
\hline Lack of or insufficient expertise on ethical review & Not completely independent \\
\hline Pressure from researchers & Pressure from sponsors \\
\hline $\begin{array}{l}\text { Lack of active or consistent participation of } \\
\text { members }\end{array}$ & Unequal treatment of applicants in review \\
\hline $\begin{array}{l}\text { Lack of recognition of the importance of REC } \\
\text { functions }\end{array}$ & \\
\hline
\end{tabular}

finding missions and consultations would existing ethics codes be analysed for their relevance to mitigating the identified risks.

After the risk research was concluded, a meticulous analysis of all identified risks for ethics dumping (chapter 5) was undertaken. All 88 risks were mapped onto existing ethics codes. For instance, Risk 8 was identified as "Poor representation of Southern (host) partners on research teams, e.g. responsible for menial tasks only or not acknowledged or represented appropriately in publications" (Singh and Schroeder 2017). The mapping exercise discovered that the best match to mitigate this risk was the Montreal Statement on Research Integrity in CrossBoundary Research Collaborations (Singh and Schroeder 2017), which notes:

\begin{abstract}
Collaborating partners should come to an agreement, at the outset and later as needed, on how publication and other dissemination decisions will be made and on standards for authorship and acknowledgement of joint research products. The contributions of all partners, especially junior partners, should receive full and appropriate recognition. (Montreal Statement 2013)
\end{abstract}

Through this exercise, it was possible to arrive at guidance to counter ethics dumping, while simultaneously identifying which risks, if any, were not covered by any notable guidance. For instance, the lack of guidance on risk management approaches to biosafety and biosecurity was discovered in this way (Singh and Schroeder 2017), leading to article $18^{13}$ of the GCC.

Once the fact-finding, consultations and analysis had been done, the drafting process began.

\title{
Drafting Process
}

The drafting committee of the GCC consisted of four people, following Michael Davis's (2007) advice:

Keep the drafting committee small. Preparing a first draft of a code is not an activity made lighter "by many hands". It is more like the soup that "too many cooks" spoil."

\footnotetext{
${ }^{13}$ In situations where environmental protection and biorisk-related regulations are inadequate or non-existent in the local setting compared with the country of origin of the researcher, research should always be undertaken in line with the higher standards of environmental protection.
} 
Table 6.7 GCC drafting committee

\begin{tabular}{l|l|l|l|l}
\hline Drafter & $\begin{array}{l}\text { Region of } \\
\text { origin }\end{array}$ & Focus & Background & Roles \\
\hline Schroeder & North & $\begin{array}{l}\text { All engagement and } \\
\text { fact-finding }\end{array}$ & $\begin{array}{l}\text { Philosophy, politics, } \\
\text { economics }\end{array}$ & Full first draft \\
\hline Chennells & South & $\begin{array}{l}\text { Vulnerable } \\
\text { populations }\end{array}$ & Law & $\begin{array}{l}\text { Drafting articles to protect } \\
\text { vulnerable populations }\end{array}$ \\
\hline Chatfield & North & Risks & $\begin{array}{l}\text { Social science, } \\
\text { philosophy }\end{array}$ & $\begin{array}{l}\text { Redrafting to ensure all } \\
\text { risks were covered }\end{array}$ \\
\hline Singh & South & Existing guidelines & Public health & $\begin{array}{l}\text { Redrafting with a focus on } \\
\text { existing guidelines }\end{array}$ \\
\hline
\end{tabular}

Table 6.7 shows the configuration of the four-person drafting committee. The emphasis was on $50 \%$ North and $50 \%$ South membership, taking into account the expertise needed and relevant background.

The four-values approach, featuring fairness, respect, care and honesty, had been adopted by the consortium at an earlier stage (chapter 3 ). Based on these values and the inputs into the GCC from consultations and fact-finding activities over two years (see Fig. 6.1), the lead author, Professor Doris Schroeder, drafted the first version, which contained 20 articles, three fewer than the final version.

For instance, article 15 on the risks of stigmatization, incrimination, discrimination and indeterminate personal risk was added during the peer review process by Professor Morton, the veterinary expert in the consortium.

Professor Schroeder's first draft was refined considerably by the social science and risk expert on the drafting committee, Dr Kate Chatfield. Dr Roger Chennells, the expert on involving vulnerable populations in research, who also provided a legal perspective, drafted his own articles on the prevention of ethics dumping. Many of these addressed the same issues identified by the lead author, but now illuminated by a legal reading. For example, article 20 on the clear understanding of roles and responsibilities was an important addition. Finally, the expert on existing guidelines, Dr Michelle Singh, checked the draft code for oversights relevant to countering ethics dumping and also, for example, added article 7 on the importance of compensating local support systems.

The first full draft agreed by the four-person committee then went through a rigorous internal peer review process in the consortium, including detailed discussions at a plenary meeting in Germany in February 2018. Each draft article was analysed in depth. Changes at this stage included:

- A different order to demonstrate importance through emphasis: for example, the assertion that the local relevance of research is essential became article 1 .

- Different wording: for example, the word "gatekeeper' in article 7 was replaced with "local coordinator", and "community approval" in article 9 was changed to "community assent".

- Regrouping to connect with a different value: for example, local ethics review was moved from the "fairness" section to "respect". 
- Combining articles: for example, showing respect to local ethics committees and producing documentation in line with local requirements were combined in the final article 11 .

Some issues could not be solved at the meeting and individual experts were tasked with presenting solutions. For instance, Professor Rachel Wynberg from the University of Cape Town, a world-leading expert on benefit sharing, was asked to ensure that the benefit-sharing articles of the GCC (articles 5 and 6) were in line with the most recent legal instruments and phrased as accessibly as possible.

Article 14 was debated with particular gusto. Part of the group wanted to prevent any research that was prohibited in HICs from taking place in LMICs, whereas others wanted to leave room for justifiable exceptions. The final version of the article was agreed through consensus-building suggestions from Professors Carel IJsselmuiden and Klaus Leisinger, which enabled permissible exceptions with a "comply or explain" proviso.

When an internal consensus was reached on the entire text, bearing in mind that "internal" involved 13 partner organizations from around the world, the agreed draft was released to the previously engaged external stakeholders, in line with further advice from Michael Davis (2007):

Make the procedure as open as possible once there is a first draft. The openness ... protects the drafting committee not only from the eccentricities of those outside the committee but from the tendency of drafting committees to forget practical constraints.

All articles were accordingly submitted to a much broader peer review by those who had previously taken part in consultations, and their comments were obtained. Many of these comments were acted upon, including:

- An industry representative's suggestion to remove the following closing sentence from the draft article on community assent: "Developing personal, longstanding relationships with local communities produces the bedrock of respect." This was on the basis that the statement did not apply to all international collaborative research, and also that no other GCC article had such a commentary.

- The request by several external stakeholders from various backgrounds that the qualification "wherever possible" be added to articles 2, 4 and 10, in order to be more realistic.

- The proposal that "vehicle drivers" be removed from the examples of local research support systems given in article 7.

After this extensive peer review, three further activities were undertaken. First, the final draft was reworked by a professional editor (Paul Wise in South Africa) to achieve the clearest, most precise and most accessible language. Second, the code was professionally designed for publication (CD Marketing Ltd, UK). Third, funding was obtained (from the University of Central Lancashire, UK, and the EDCTP) to translate the code into Russian, French, Spanish, German, Portuguese, Mandarin, Japanese, and Hindi. ${ }^{14}$ Arabic and isiXhosa translations are in progress as this book goes to press.

\footnotetext{
${ }^{14}$ The translations can be found at http://www.globalcodeofconduct.org/open-to-the-world/
} 


\section{Early Adopters and Conclusion}

After an intensive and scrupulous development process, the GCC was launched at two high-profile events. First, at a meeting of the UN Leadership Council for Sustainable Development in Stockholm, Sweden, in May 2018, and then at the European Parliament in June 2018. The GCC had been under examination by the ethics and integrity sector and the legal services of the EC since March 2018. This allowed Dr Wolfgang Burtscher, Deputy Director-General for Research and Innovation of the EC, to announce the big news at the European Parliament event: the GCC would be a mandatory reference document for the framework programmes that fund European research. What this means was expressed succinctly in a Nature article.

Ron Iphofen, an adviser on research ethics to the European Commission, believes the code will have a profound impact on how funding proposals to the EU are designed and reviewed. "I could envisage reviewers now looking suspiciously at any application for funds that entailed research by wealthy nations on the less wealthy that did not mention the code," he says. (Nordling 2018)

Two months later, in August 2018, the EDCTP announced that henceforth its applicants would be required to comply with the GCC. In April 2019, the Senate of the University of Cape Town (UCT) adopted the GCC as the first university globally to ensure that UCT researchers maintain the highest ethical standards.

The groundwork for developing the GCC included a broad collation of ethics dumping case studies, as well as good practice examples from international collaborative research, and extensive consultation with representatives from a range of stakeholder groups: research policymakers, research funders including private industry, researchers, research communities, research ethics committees and, most importantly, vulnerable research participants and those who support them. Building on 88 generic risks identified in the fact-finding and consultation phases of the TRUST project, and taking existing guidelines into account, a code was built which will provide guidance across all research disciplines. It focuses on research collaborations between LMIC and HIC partners, which often involve considerable imbalances of power, resources and knowledge. The GCC is presented in 23 clear, short statements in order to achieve the highest possible cross-cultural accessibility for researchers, funders and vulnerable populations alike.

Those who apply the GCC are demonstrating that they oppose double standards in research and support long-term equitable research relationships between partners from LMIC and HIC settings, based upon the values of fairness, respect, care and honesty.

\section{References}

Bassler A, Brasier K, Fogel N, Taverno R (2008) Developing effective citizen engagement: a howto guide for community leaders. Center for Rural Pennsylvania, Harrisburg PA. http://www. rural.palegislature.us/effective_citizen_engagement.pdf 
Burtscher W (2018) TRUST Global Code of Conduct to be a reference document applied by all research projects applying for H2020 funding. TRUST eNewsletter Issue 5. http://www.globalcodeofconduct.org/wp-content/uploads/2018/12/TRUSTNewsletter_2018_Issue5.pdf

Chatfield K, Schroeder D, Kimani J (2016a) Vulnerable populations in North-South collaborative research: Nairobi plenary 2016. A report for TRUST. http://trust-project.eu/wp-content/ uploads/2016/11/Meeting-Report-TRUST-Nairobi-Final.pdf

Chatfield K, Schroeder D, Muthuswamy V (2016b) Mumbai case studies meeting. A report for TRUST. http://trust-project.eu/wp-content/uploads/2016/06/Mumbai-Case-Studies-Workshop. pdf

Cook WK (2008) Integrating research and action: a systematic review of community-based participatory research to address health disparities in environmental and occupational health in the United States. Journal of Epidemiology and Community Health 62(8):668-676. https://doi. org/10.1136/jech.2007.067645

Dammann J, Cavallaro F (2017) First engagement report. A report for TRUST. http://trust-project. eu/wp-content/uploads/2016/03/TRUST-1st-Engagement-Report_Final.pdf

Dammann J, Schroeder D (2018) Second engagement report. A report for TRUST. http://trustproject.eu/wp-content/uploads/2018/12/TRUST-2nd-Engagement-Report-Final.pdf

Davis M (2007) Eighteen rules for writing a code of professional ethics. Science and Engineering Ethics 13(2):171-189.

Dunn A (2011) Community engagement: under the microscope. Wellcome Trust, London. https:// wellcome.ac.uk/sites/default/files/wtvm054326_0.pdf

European Commission (2013) Declarations of the Commission (framework programme) 2013/C 373/02. Official Journal of the European Union 20 December. http://ec.europa.eu/research/ participants/data/ref/h2020/legal_basis/fp/h2020-eu-decl-fp_en.pdf

Eurostat (2018) Intramural R\&D expenditure (GERD) by source of funds. https://ec.europa.eu/ eurostat/web/products-datasets/product?code=rd_e_gerdfund

Gallo AM., Angst DB, Knafl KA (2009) Disclosure of genetic information within families. The American Journal of Nursing 109(4):65-69. http://www.ncbi.nlm.nih.gov/pubmed/19325321

Hebert JR, Brandt HM, Armstead CA, Adams SA, Steck SE (2009) Interdisciplinary, translational, and community-based participatory research: finding a common language to improve cancer research. Cancer Epidemiology, Biomarkers \& Prevention 18(4):1213-1217. https://doi. org/10.1158/1055-9965.EPI-08-1166

Horizon 2020 (nd) Evaluation of proposals. Research and Innovation, European Commission. http://ec.europa.eu/research/participants/docs/h2020-funding-guide/grants/ from-evaluation-to-grant-signature/evaluation-of-proposals_en.htm

Jack A (2012) Wellcome challenges science journals. Financial Times, 10 April. https://www. ft.com/content/81529c58-8330-11e1-ab78-00144feab49a

Kelman A, Kang A, Crawford B (2019) Continued access to investigational medicinal products for clinical trial participants: an industry approach. Cambridge Quarterly of Healthcare Ethics 28(1):124-133. https://www.cambridge.org/core/product/identifier/S0963180118000464/ type/journal_article

Kessel M (2014) Restoring the pharmaceutical industry's reputation. Nature Biotechnology 32:983-990. https://doi.org/10.1038/nbt.3036

Koshy K, Liu A, Whitehurst K, Gundogan B, Al Omran Y (2017) How to hold an effective meeting. International Journal of Surgery: Oncology 2(5):e22. Available at: http://www.ncbi.nlm. nih.gov/pubmed/29732455

Levine R (2004) Research ethics committees. In: Post S (ed) Encyclopedia of bioethics, 3rd edn. Thomson \& Gale, New York, p 2311-2316

Montreal Statement (2013) Montreal statement on research integrity in cross-boundary research collaborations. http://ethics.iit.edu/codes/WCRI\%202013.pdf

Morton D, Chatfield K (2018) The use of non-human primates in research. In: Schroeder D, Cook J, Hirsch F, Fenet S, Muthuswamy V (eds) Ethics dumping: case studies from North-South research collaborations. Springer Briefs in Research and Innovation Governance, Berlin, p 81-89 
Nordling L (2018) Europe's biggest research fund cracks down on "ethics dumping". Nature 559:17-18. https://www.nature.com/articles/d41586-018-05616-w

Nyika A, Kilama W, Chilengi R, Tangwa G, Tindana P, Ndebele P, Ikingura J (2009) Composition, training needs and independence of ethics review committees across Africa: are the gatekeepers rising to the emerging challenge? Journal of Medical Ethics 35(3):189-193

Rogelberg SG, Leach DJ, Warr PB, Burnfield J L (2006) "Not another meeting!" Are meeting time demands related to employee well-being? Journal of Applied Psychology 91(1):83-96

Schroeder D, Cook J, Hirsch F, Fenet S, Muthuswamy, V (eds) (2018) Ethics dumping: case studies from North-South research collaborations, Springer Briefs in Research and Innovation Governance, Berlin

Schroeder D, Tavlaki E (2018) 2nd pictorial report. A report for TRUST. http://trust-project.eu/ wp-content/uploads/2018/12/TRUST-2nd-Pictorial-Report.pdf

Singh M, Makanga M (2017) Funder platform. A report for TRUST. http://trust-project.eu/wpcontent/uploads/2017/09/Funder-Platform-Report_20-Sep-2017_funder-approved.pdf

Singh M, Schroeder D (2017) Exploitation risks and research ethics guidelines. A report for TRUST. $\quad$ http://trust-project.eu/wp-content/uploads/2016/03/TRUST-Deliverable-RisksPrinciples-Final-for-submission.pdf

TRUST (2018) Strong speech by Nairobi activist in European Parliament. http://trust-project.eu/ strong-speech-by-nairobi-activist-in-european-parliament/

United Nations (nda) Goal 3. Sustainable Development Goals. https://www.un.org/ sustainabledevelopment/health/

United Nations (ndb) Goal 8. Millennium Development Goals. http://www.un.org/millenniumgoals/global.shtml

Van Niekerk J, Wynberg R (2018) Human food trial of a transgenic fruit. In: Schroeder D, Cook J, Hirsch F, Fenet S, Muthuswamy V (eds) Ethics dumping: case studies from North-South research collaborations. Springer Briefs in Research and Innovation Governance, Berlin, p 91-98

Van Niekerk J, Wynberg R, Chatfield K (2017). Cape Town plenary meeting report. TRUST Project. http://trust-project.eu/wp-content/uploads/2017/08/TRUST-Kalk-Bay-2017-ReportFinal.pdf

WMA (2013) Declaration of Helsinki. World Medical Association. https://www.wma.net/policiespost/wma-declaration-of-helsinki-ethical-principles-for-medical-research-involving-humansubjects/

Wynberg R, Schroeder D, Chennells R (2009) Indigenous peoples, consent and benefit sharing: lessons from the San-Hoodia case. Springer, Berlin

Youdelis M (2016) "They could take you out for coffee and call it consultation!" The colonial antipolitics of indigenous consultation in Jasper National Park. Environment and Planning A: Economy and Space 48(7):1374-1392

Open Access This chapter is licensed under the terms of the Creative Commons Attribution 4.0 International License (http://creativecommons.org/licenses/by/4.0/), which permits use, sharing, adaptation, distribution and reproduction in any medium or format, as long as you give appropriate credit to the original author(s) and the source, provide a link to the Creative Commons licence and indicate if changes were made.

The images or other third party material in this chapter are included in the chapter's Creative Commons licence, unless indicated otherwise in a credit line to the material. If material is not included in the chapter's Creative Commons licence and your intended use is not permitted by statutory regulation or exceeds the permitted use, you will need to obtain permission directly from the copyright holder.

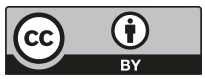

